\title{
Estimation of Rice Crop Quality and Harvest Amount from Helicopter Mounted NIR Camera Data and Remote Sensing Satellite Data
}

\author{
Kohei Arai 1 \\ Graduate School of Science and Engineering \\ Saga University \\ Saga City, Japan \\ Masanoori Sakashita ${ }^{1}$ \\ Information Science, Saga University \\ Saga, Japan
}

\author{
Osamu Shigetomi ${ }^{2}$ \\ Saga Prefectural Agricultural Research Institute \\ Saga Prefectural Government, \\ Japan \\ Yuko Miura $^{2}$ \\ Saga Prefectural Agricultural Research Institute \\ Saga Prefectural Government, Japan
}

\begin{abstract}
Estimation of rice crop quality and harvest amount in paddy fields with the different rice stump density derived from helicopter mounted NIR camera and remote sensing satellite data is made. Using the intensive study site of rice paddy fields with managing, estimation of protein content in rice crop and nitrogen content in rice leaves through regression analysis with Normalized Difference Vegetation Index: NDVI derived from camera mounted on a radio-control helicopter is made together with harvest amount of rice crops. Through experiments at rice paddy fields which is situated at Saga Prefectural Agriculture Research Institute SPRIA in Saga city, Japan, it is found that protein content in rice crops is highly correlated with NDVI which is acquired with visible and Near Infrared: NIR camera mounted on radio-control helicopter. It also is found that nitrogen content in rice leaves is correlated to NDVI as well. Protein content in rice crop is negatively proportional to rice taste. Therefore rice crop quality can be evaluated through NDVI observation of rice paddy field.
\end{abstract}

Keywords-Rice Crop; Rice Leaf; Nitrogen content; Protein content; NDVI

\section{INTRODUCTION}

Vitality monitoring of vegetation is attempted with photographic cameras [1]. Grow rate monitoring is also attempted with spectral reflectance measurements [2]. BiDirectional Reflectance Distribution Function: BRDF is related to the grow rate for tealeaves [3]. Using such relation, sensor network system with visible and near infrared cameras is proposed [4]. It is applicable to estimate nitrogen content and fiber content in the tealeaves in concern [5]. Therefore, damage grade can be estimated with the proposed system for rice paddy fields [6]. This method is validated with Monte Carlo simulation [7]. Also Fractal model is applied to representation of shapes of tealeaves [8]. Thus the tealeaves can be asse3ssed with parameters of the fractal model. Vitality of tea trees are assessed with visible and near infrared camera data [9]. Rice paddy field monitoring with radio-control helicopter mounting visible and Near Infrared: NIR camera is proposed [10] while the method for rice quality evaluation through nitrogen content in rice leaves is also proposed [11].
The method proposed here is to evaluate rice quality through protein content in rice crop with observation of Normalized Difference Vegetation Index: NDVI which is acquired with visible and NIR camera mounted on radio-control helicopter as well as remote sensing satellite data1. Spatial resolution of Advanced Spaceborne Thermal Emission and Reflection Radiometer: ASTER/Visible to Near Infrared radiometer: VNIR is $15 \mathrm{~m}$ and is good enough for evaluation of rice sump density effect on quality and harvest amount.

The fact that protein content in rice crops is highly correlated with NDVI which is acquired with visible and Near Infrared: NIR camera mounted on radio-control helicopter is well reported [10]. It also is reported that nitrogen content in rice leaves is correlated to NDVI as well. Protein content in rice crop is negatively proportional to rice taste. Therefore rice crop quality can be evaluated through NDVI observation of rice paddy field. Relation among nitrogen content in rice leaves, amount of fertilizer, NDVI and protein content in rice crops has to be clarified [11]. There are some indexes which show quality of rice crops, protein content, nitrogen content, etc. in the rice leaves. Meanwhile, there are some indexes for harvest amount, the number of ear in the stump, ear length, crop weight, etc. It should be depending on circumstances of geometric condition, soil condition, meteorological condition, water supply condition, fertilizer amount and rice stump density. Intensive study paddy fields have a variety of conditions. Helicopter mounted NIR camera has a good enough spatial resolution. Therefore, rice crop quality and harvest amount is evaluated as a function of water supply condition and fertilizer amount and rice stump density. Spatial resolution of remote sensing satellite mounted visible to near infrared radiometers, however, are not so fine enough for the rice paddy fields in the sites. Therefore, only stump density influence on rice crop quality and harvest amount is evaluated with remote sensing satellite data.

\footnotetext{
${ }^{1}$ ASTER(Advanced Space based radiometer for Thermal Emission and Reflection)/VNIR(Visible to Near Infrared Radiometer) which is onboard Terra satellite has three spectral channels (Green, Red, and Near Infrared) with $15 \mathrm{~m}$ of spatial resolution.
} 
Hiyokumochi rice is our major concern. In the intensive study paddy field, Hiyokumochi rice is planted for the research. Hiyokumochi of rice species is a new species. Therefore, appropriate grow process is unknown. One of the other purposes of this research works is to clarify an appropriate grow process, in particular, the number of ear and the number of rice in a unit area is major concern.

The method used for rice crop quality and harvest amount evaluations is described in the next section followed by experiments. The experimental results are validated in the following section followed by conclusion with some discussions.

\section{PROPOSED SYSTEM}

\section{A. Radio Controlled Helicopter Based Near Infrared}

Cameras Utilizing Agricultural Field Monitoring System

The helicopter used for the proposed system is "GrassHOPPER" manufactured by Information \& Science Techno-Systems Co. Ltd. The major specification of the radio controlled helicopter used is shown in Table 1. Canon Powershot $\mathrm{S} 100^{3}$ (focal length $=24 \mathrm{~mm}$ ) is mounted on the GrassHOPPER. The filter of blue band is replaced to the NIR filter. Therefore, Green, Red and NIR bands of images can be obtained with this camera. It allows acquire images with the following Instantaneous Field of View: IFOV at the certain altitudes, $1.1 \mathrm{~cm}$ (Altitude $=30 \mathrm{~m}$ ) $3.3 \mathrm{~cm} \quad$ (Altitude $=100 \mathrm{~m}$ )

and $5.5 \mathrm{~cm}$ (Altitude $=150 \mathrm{~m})$.

TABLE I. MAJOR SPECIFICATION OF GRASSHOPPER

\begin{tabular}{|c|c|}
\hline Weight & $2 \mathrm{~kg}$ (Helicopter only) \\
\hline Size & $80 \mathrm{~cm} \times 80 \mathrm{~cm} \times 30 \mathrm{~m}$ \\
\hline Payload & $600 \mathrm{~g}$ \\
\hline
\end{tabular}

Radio wave controlled helicopter mounted near infrared camera imagery data is acquired at $\mathrm{A}$ and $\mathrm{B}$ paddy fields in SPRIA on 8 October 2014 with the different viewing angle from the different altitudes. Figure 5 shows an example of the acquired near infrared image. There is spectralon ${ }^{4}$ of standard plaque as a reference of the measured reflectance in between $\mathrm{A}$ and $\mathrm{B}$. Just before the data acquisition, some of rice crops and leaves are removed from the subsection of paddy fields for inspection of nitrogen content. Using the removed rice leaves, nitrogen content in the rice leaves is measured based on the Kjeldahl method ${ }^{5}$ and Dumas method ${ }^{6}$ (a kind of chemical method) with Sumigraph $\mathrm{NC}-220 \mathrm{~F}^{7}$ of instrument. The measured total nitrogen content in rice leaves and protein content in rice crops are compared to the NDVI.

\section{B. Rice Crop Field at Saga Prefectural Agriculture Research Institute: SPARI}

Specie of the rice crop is Hiyokumochi ${ }^{8}$ which is one of the late growing types of rice species. Hiyokumochi is one of low amylase (and amylopectin rich) of rice species (Rice No.216).

Figure 1 shows the Location (a) and (b) Layout of the test site of rice crop field at SPRIA which is situated at $33^{\circ} 13^{\prime} 11.5^{\prime \prime}$ North, $130^{\circ} 18^{\prime} 39.6^{\prime \prime}$ East, and the elevation of 52 feet on the Google map. B and A in the Figure 1 (b) shows intensive study rice paddy fields. Figure 2 shows the superimposed image of SPARI paddy field layout on Google map. There are the test sites A and B investigation of nitrogen of chemical fertilizer dependency on rice crop quality as shown in Figure 3. There are two types of paddy subsections, densely and sparsely planted paddy fields. Hiyokumochi rice leaves are planted 15 to 20 stumps per $\mathrm{m}^{2}$ on June 222014. Rice crop fields are divided into 10 different small fields depending on the amount of nutrition including nitrogen ranges from zero to $19 \mathrm{~kg} / 10 \mathrm{a} /$ nitrogen.

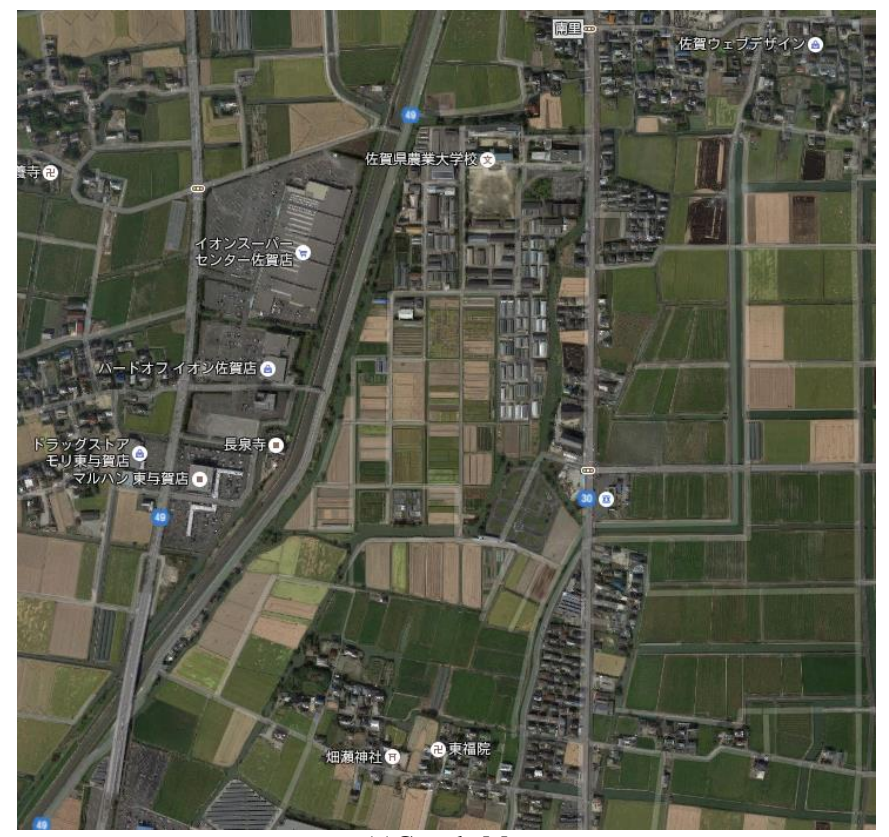

(a)Google Map

\footnotetext{
${ }^{2}$ http://www.ists.co.jp/?p=789

3 http://cweb.canon.jp/camera/dcam/lineup/powershot/s100/

${ }^{4}$ https://en.wikipedia.org/wiki/Spectralon

${ }^{5}$ https://en.wikipedia.org/wiki/Kjeldahl_method

${ }^{6} \mathrm{https} / / /$ en.wikipedia.org/wiki/Dumas_method

${ }^{7}$ http://www.hok-chem.co.jp/products/food/NC-220F.html
}

\footnotetext{
${ }^{8}$ https://ja.wikipedia.org/wiki/\%E3\%82\%82\%E3\%81\%A1\%E7\%B1\%B3
} 


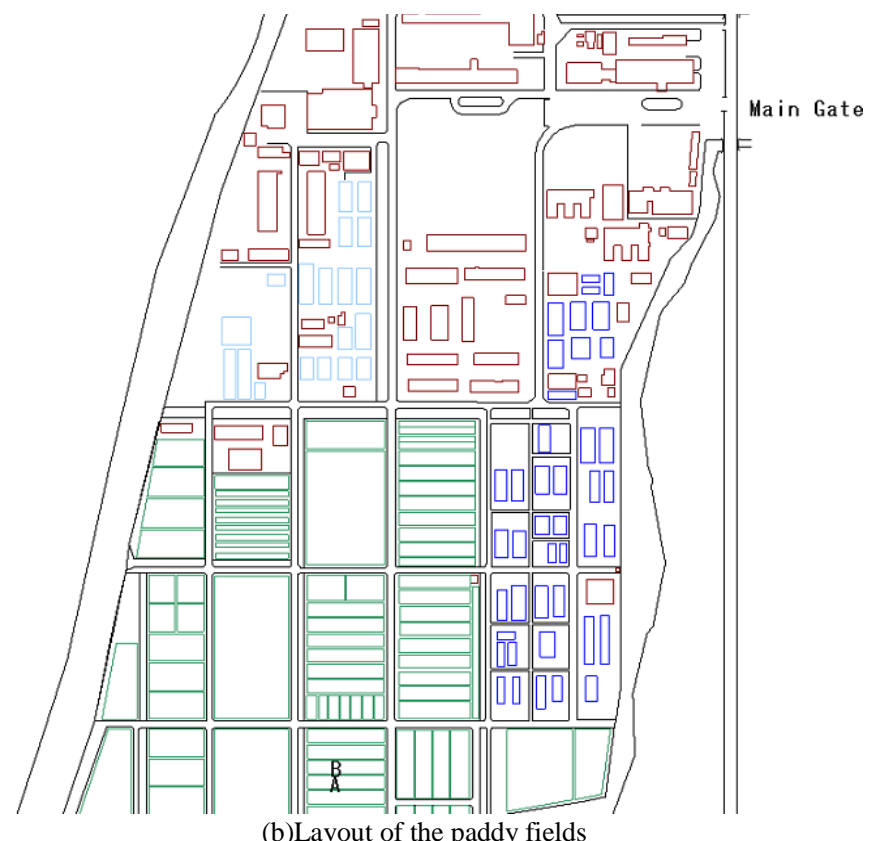

Fig. 1. Location of Saga Prefectural Agriculture Research Institute: SPARI on Google map

Nitrogen of chemical fertilizer is used to put into paddy fields for five times during from June to August. Although rice crops in the 10 different small fields are same species, the way for giving chemical fertilizer are different. Namely, the small field No.1 is defined as there is no chemical fertilizer at all for the field while 9,11 , and $13 \mathrm{~kg} / 10 \mathrm{a} /$ nitrogen of after chemical fertilizer are given for No.2 to 4, respectively, no initial chemical fertilizer though. Meanwhile, $9,11,13 \mathrm{~kg} / 10$ a/nitrogen are given as after chemical fertilizer for the small field No.5, 6, and 7, respectively in addition to the $3 \mathrm{~kg} / 10$ a/nitrogen of initial chemical fertilizer. On the other hand, 12, 14 , and $16 \mathrm{~kg} / 10$ a /nitrogen are given for the small fields No.5, 6, 7, respectively as after chemical fertilizer in addition to the initial chemical fertilizer of $3 \mathrm{~kg} / 10 \mathrm{a} /$ nitrogen for the small field No. 15, 17, 19, respectively. Therefore, rice crop grow rate differs each other paddy fields depending on the amount of nitrogen of chemical fertilizer.

\section{EXPERIMENTS}

\section{A. Relations between Measured Indexes and NDVI Measured with Helicopter Mounted NIR Camera}

The experiment is conducted on October 32014 just before harvest. Figure 4 shows the NIR camera acquired image of the intensive study paddy fields A and B. There are two types of indexes, (1) rice crop quality and (2) harvest amount related indexes are measured. Those are (1) Protein Content in rice crops and SPAD (Greenness of the rice leaves) and (2) Ear Length, the Number of Ear per square meter and Crop Weight per 10a. Namely, protein rich rice crops taste bad while high SPAD means well grown rice leaves (such rice crop with high SPAD tastes good). Regression analysis is made between the measured indexes and the Normalized Difference Vegetation Index: NDVI measured with helicopter mounted NIR camera data.

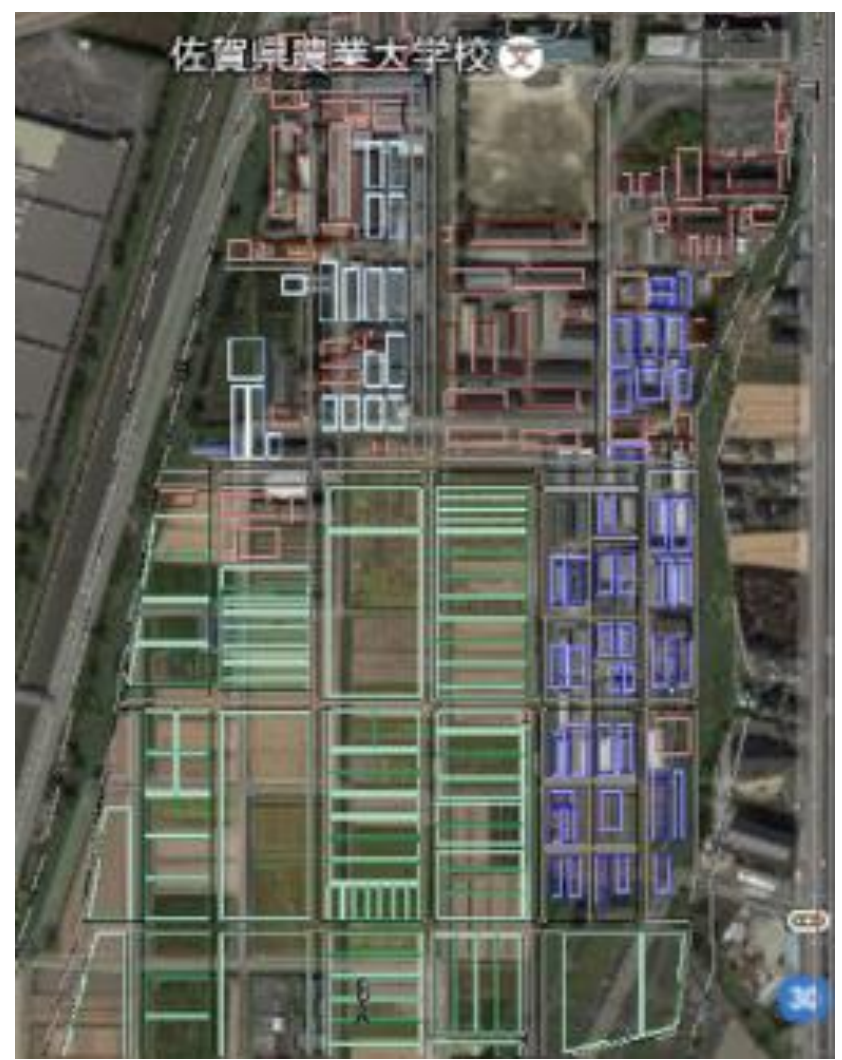

Fig. 2. Superimposed image of SPARI on Google map

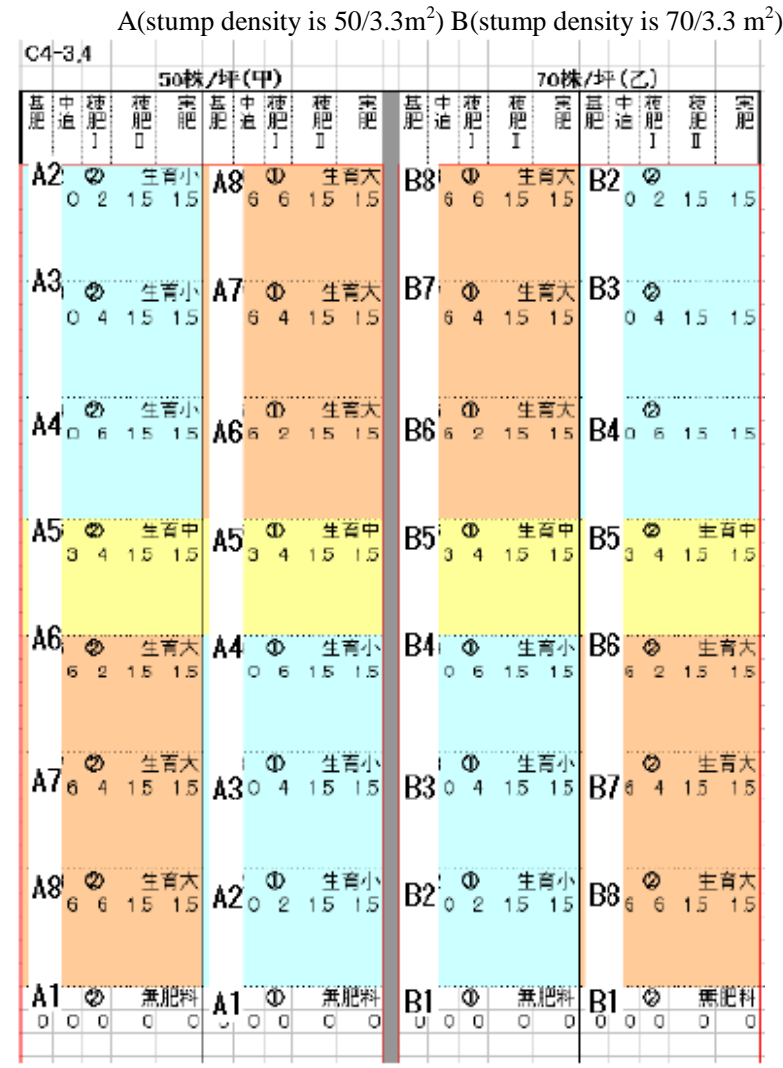

Fig. 3. Paddy filed layout for investigation of nitrogen of chemical fertilizer dependency on rice crop quality 
All the indexes are measured on October 10 2014. Figure 5 shows relations between the measured NDVI and the indexes measured for the intensive study paddy field A.

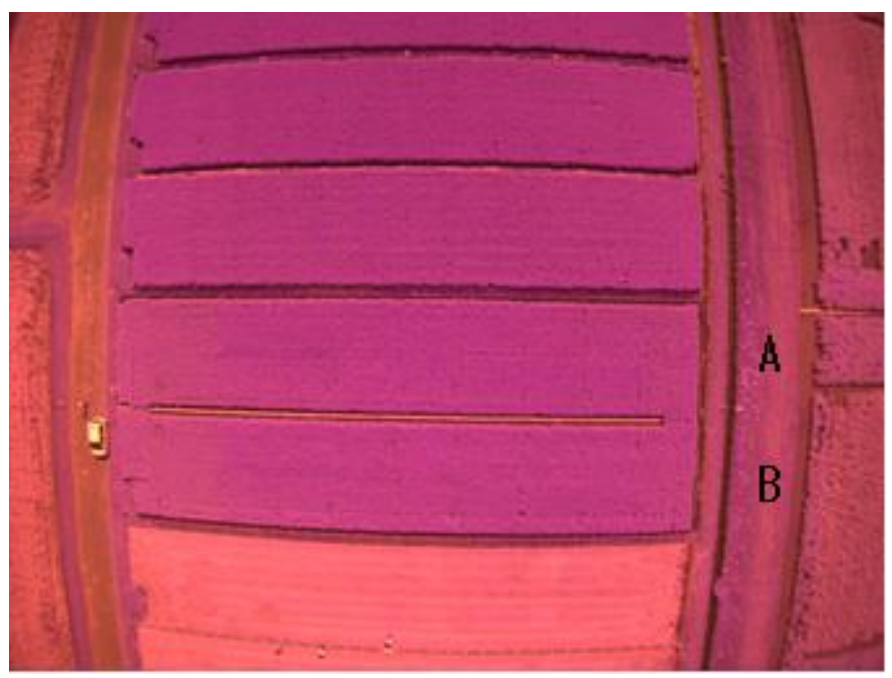

Fig. 4. NIR camera acquired image of the intensive study paddy fields A and B

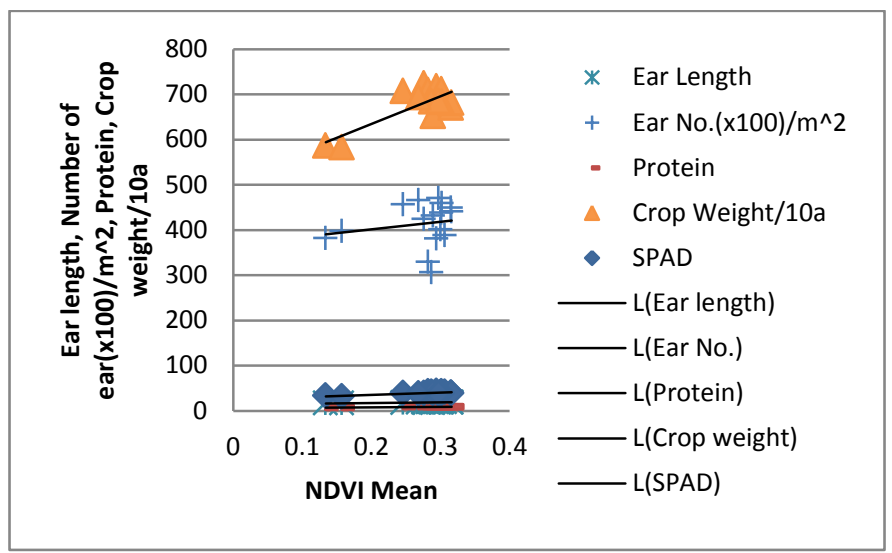

(a)Crop weight/10a and Ear number per $\mathrm{m}^{2}$

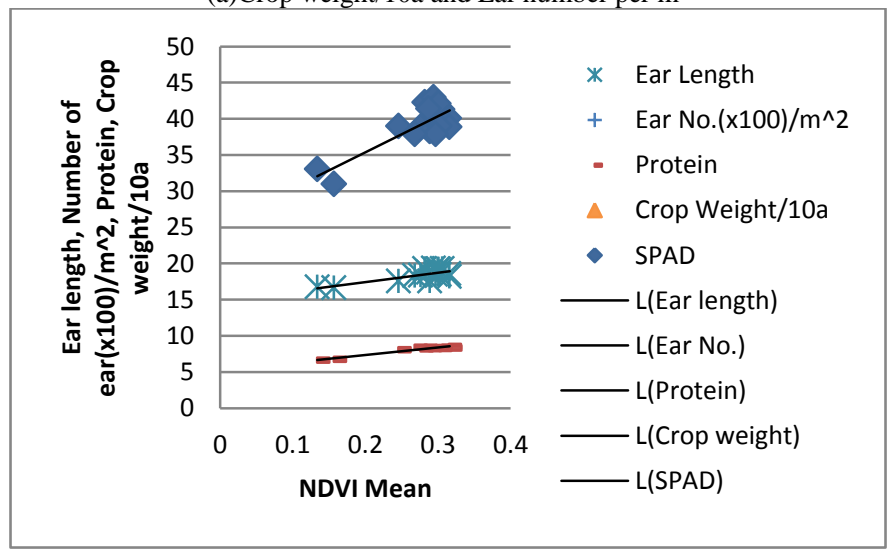

(b)Protein, Ear Length, and SPAD

Fig. 5. Rice crop quality and harvest amount related indexes

The regressive equation and $R^{2}$ for intensive study paddy field A (Stump density is $50 / 3.3 \mathrm{~m}^{2}$ ) are shown in equation (1) to (5), respectively. Namely, the equations (1) to (5) are for the Crop Weight / 10a, the Number of $\operatorname{Ear}(\mathrm{x} 100) / \mathrm{m}^{2}$, SPAD, the Protein Content in the rice crops and the Ear Length.

$$
\begin{aligned}
& y=610.6 x+512.56 \\
& R^{2}=0.6159 \\
& y=166.44 x+368.21 \\
& R^{2}=0.0338 \\
& y=12.99 x+14.849 \\
& R^{2}=0.643 \\
& y=10.252 x+5.3054 \\
& R^{2}=0.919 \\
& y=50.017 x+25.383 \\
& R^{2}=0.6904
\end{aligned}
$$

Also, Figure 6 shows relations between the measured NDVI and the indexes measured for the intensive study paddy field B. Regressive analysis is made for the intensive study paddy field $B$, The regressive equations and $R$ squares shown in equation (6) to (10), respectively. In comparison of the protein content between intensive study paddy fields $A$ and $B$, the protein content of $\mathrm{A}$ is little bit higher than that of $\mathrm{B}$. Protein rich rice crops are grown in the paddy field with sparse stump density rather than dense stump density. On the other hand, crop weight / 10a of the dense stump density of paddy field is higher than the of the sparse stump density of paddy field.

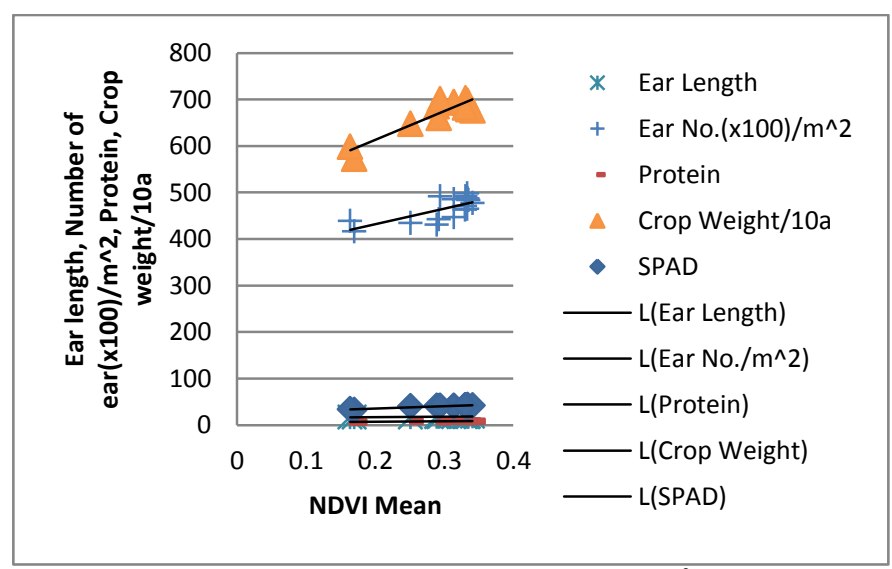

(a)Crop weight/10a and Ear number per $\mathrm{m}^{2}$

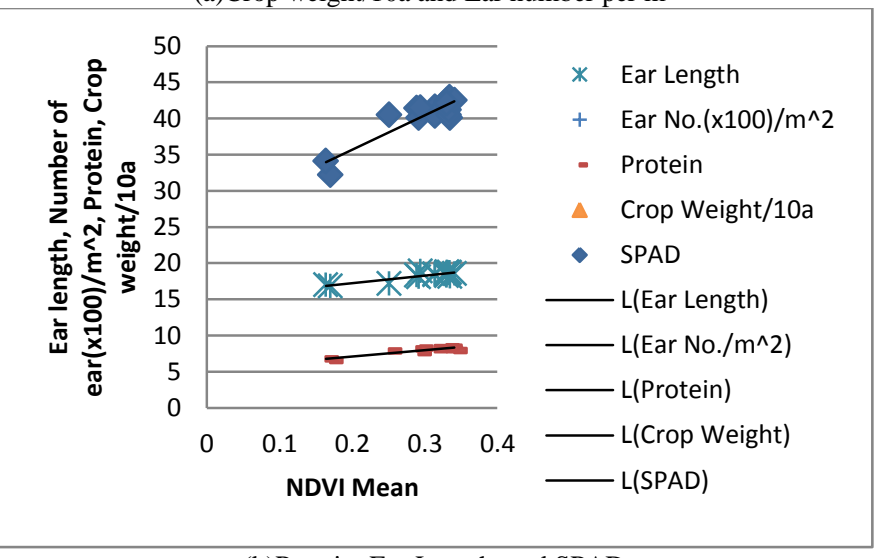

(b)Protein, Ear Length, and SPAD

Fig. 6. Rice crop quality and harvest amount related indexes

$$
\begin{aligned}
& y=616.87 x+490.02 \\
& R^{2}=0.8514 \\
& y=332.48 x+365.5
\end{aligned}
$$


$R^{2}=0.5276$

$y=10.395 x+15.133$

$R^{2}=0.7926$

$y=8.8038 x+5.3074$

$y=47.279 x+26.231$

$R^{2}=0.8168$

That is the same thing for the Number of $\operatorname{Ear}(\mathrm{x} 100) / \mathrm{m}^{2}$.
amely, the number of ear(x100) $/ \mathrm{m}^{2}$ of the dense stump density of paddy field is greater than the of the sparse stump density of paddy field while SPAD $^{9}$ of the dense stump density of paddy field is higher than the of the sparse stump density of paddy field. Meanwhile, the Ear Length of the dense stump density of paddy field is longer than the of the sparse stump density of paddy field.

\section{B. Relations between Protein Content and Harvest Amount and NDVI Measured with Helicopter Mounted NIR \\ Camera}

In more detail, there are 8 subdivisions in the same intensive study paddy fields $\mathrm{A}$ and $\mathrm{B}, \mathrm{A} 1$ to $\mathrm{A} 8$ and $\mathrm{B} 1$ to $\mathrm{B} 8$, respectively. Also, the subdivisions are separated into two sets of subdivisions. The protein content and the harvest amount of these 16 different subdivisions are plotted in Figure 7.

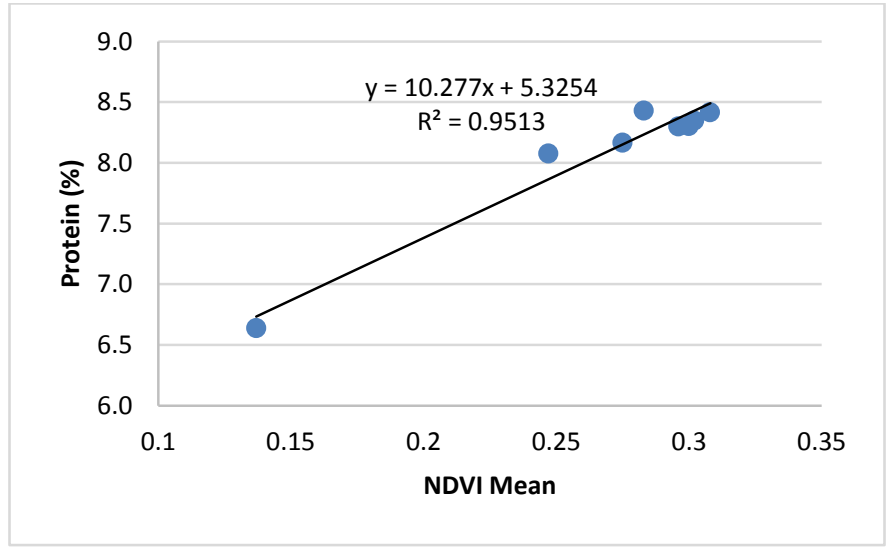

(a)Protein for $\mathrm{A}$

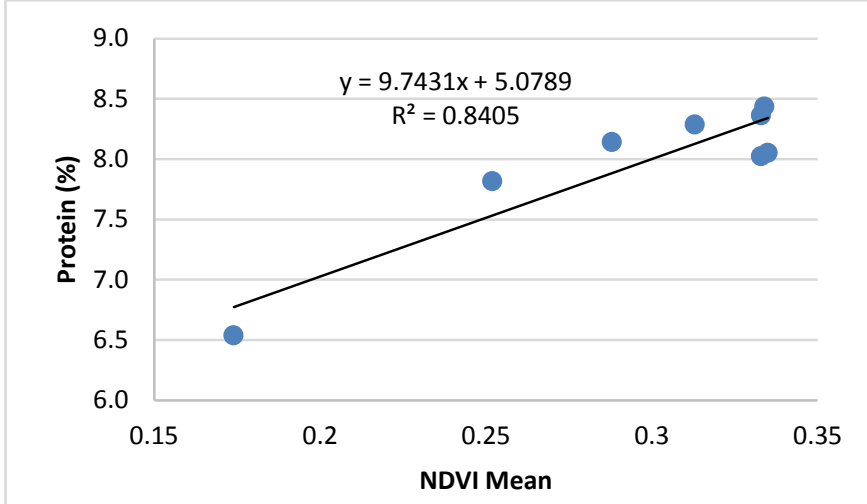

(b)Protein for B

\footnotetext{
${ }^{9}$ Soil \& Plant Analyzer Development: SPAD, chlorophyll meter
}

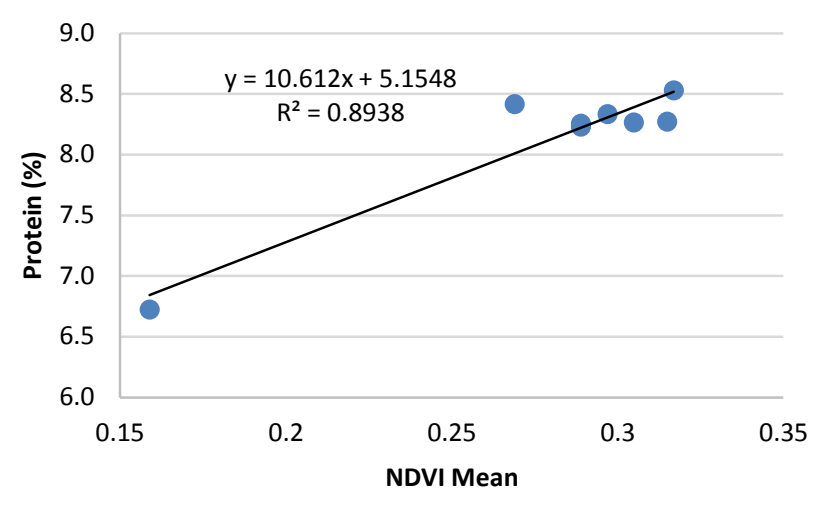

(c)Protein for A'

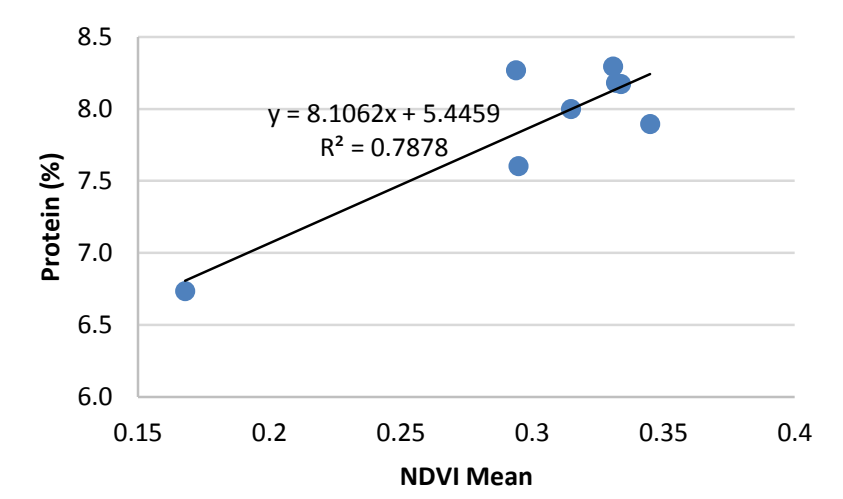

(d)Protein for B'

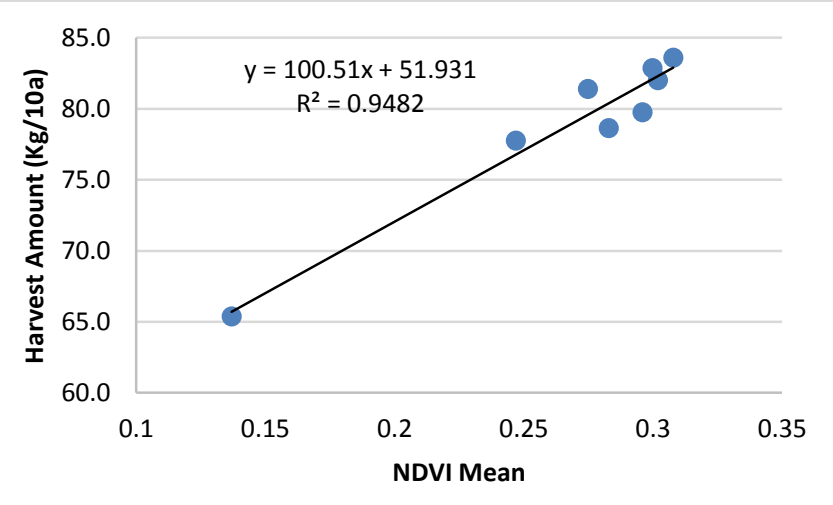

(e)Harvest amount for A

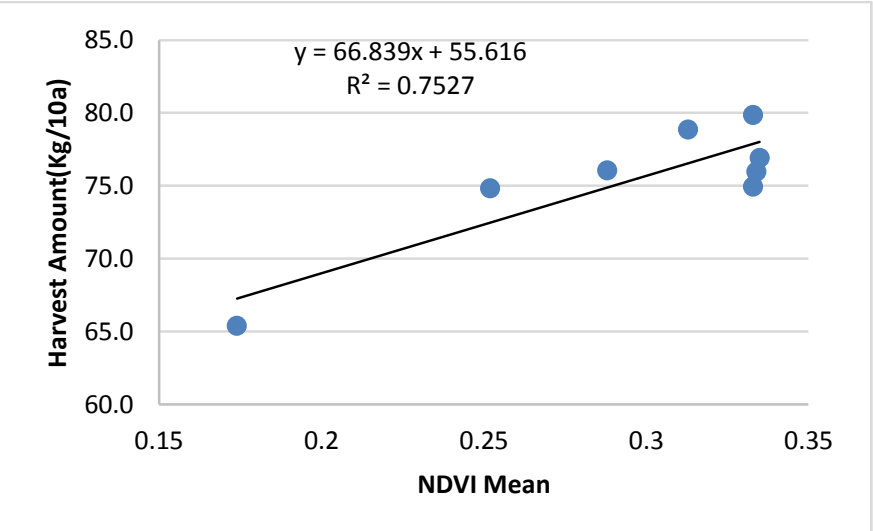

(f)Harvest amount for B 

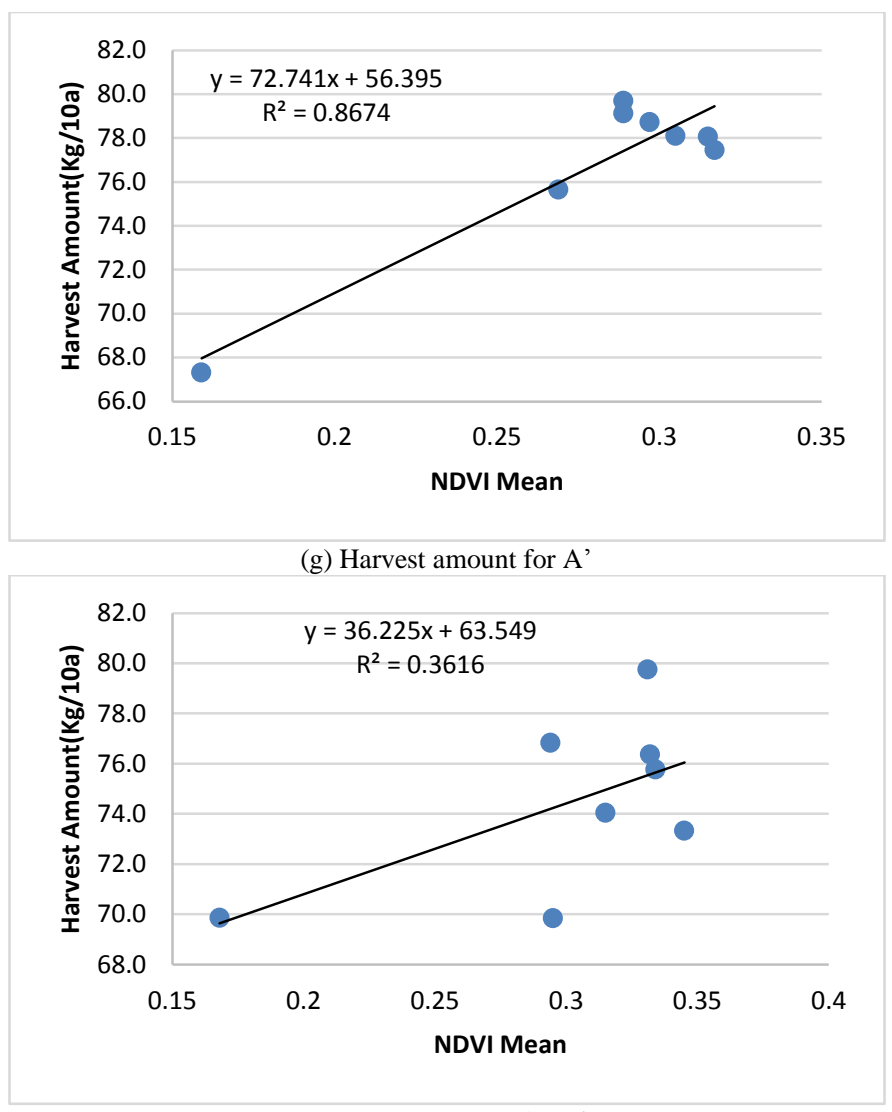

(h)Harvest amount for B'

Fig. 7. Relations between NDVI and protein content as well as harvest amount

The relation between NDVI and protein content is better than that between NVDI and harvest amount. Also, the relations between NDVI and protein content as well as harvest amount for intensive study paddy field A (sparse stump density) are better than those for paddy field B (dense stump density).

\section{Relations between Measured Indexes and NDVI Measured with ASTER/VNIR Data}

ASTER/VNIR data is acquired on October 8 2014. The small portion of ASTER/VNIR image is shown in Figure 8 (a). In the middle of the image, SPARI is situated. Figure 8 (b) and (c) shows the superimposed image of ASTER/VNIR image on Google map, the superimposed image of ASTER/VNIR image on layout map, and NDVI pixels which correspond to the intensive study paddy fields $\mathrm{A}$ and $\mathrm{B}$, respectively. Table 2 shows NDVI of the pixels corresponding to the paddy fields A and $\mathrm{B}$. NDVI of the paddy field A is $15 \%$ greater than that of the paddy field $\mathrm{B}$. The result is identical to the result form regressive analysis of protein content with NDVI. These are the same for harvest amount.

TABLE II. NDVI of THE PIXEls CORRESPONDING TO THE PADDY FIELDS A AND B

\begin{tabular}{|l|l|l|l|l|l|}
\hline$\# 1$ & $\# 2$ & $\# 3$ & $\# 4$ & $\# 5$ & Average \\
\hline 0.3083 & 0.125 & 0.125 & 0.2286 & 0.2459 & 0.20656 \\
\hline 0.232 & 0.1818 & 0.0952 & 0.0952 & 0.2462 & 0.17008 \\
\hline
\end{tabular}
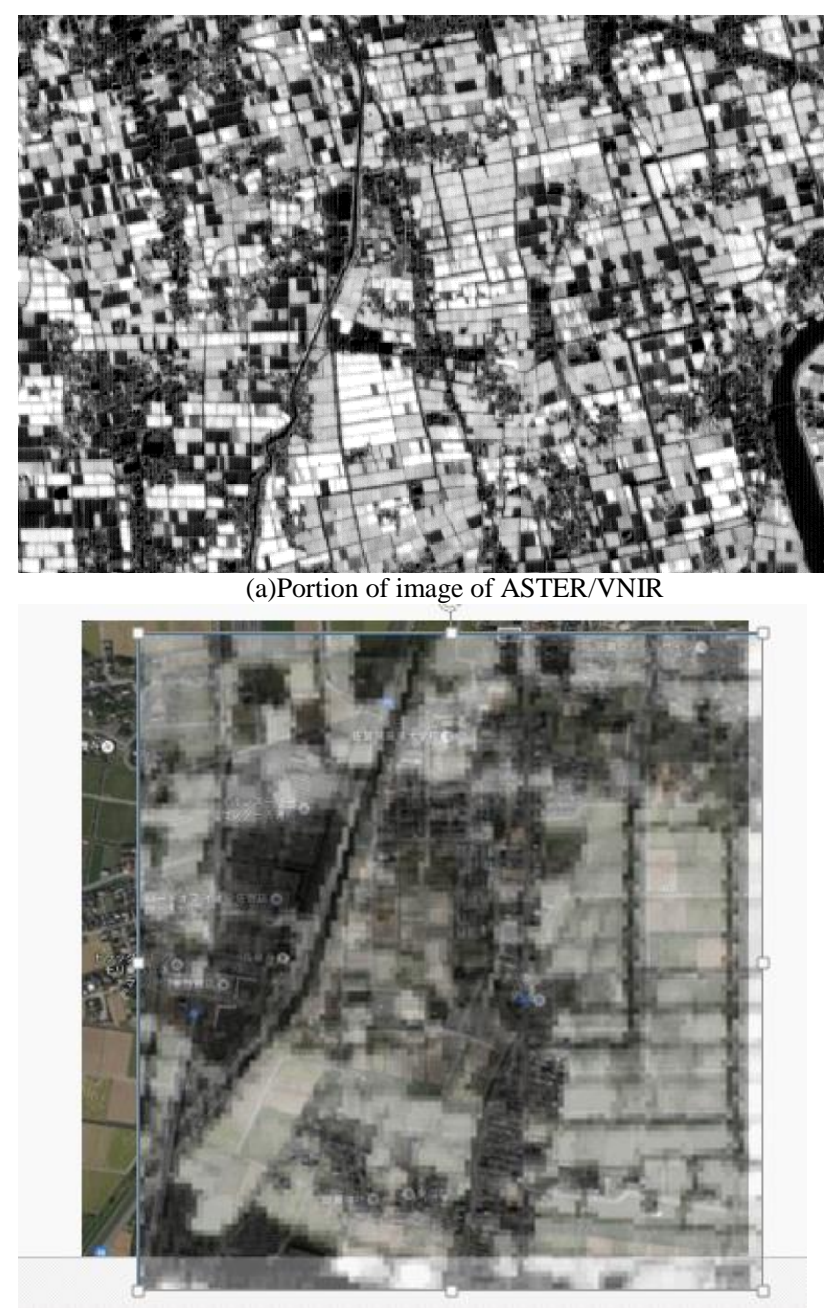

(b)Superimposed image between Google map and ASTER/VNIR

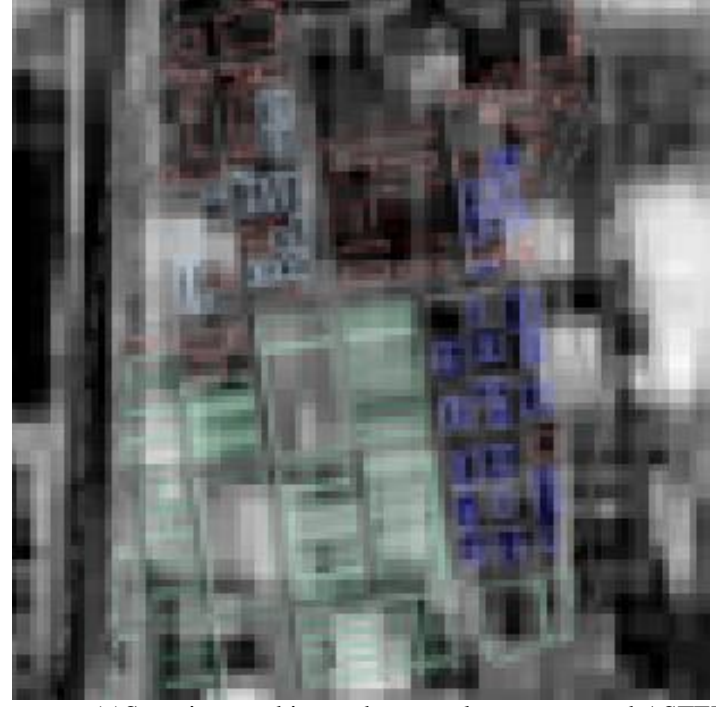

(c)Superimposed image between layout map and ASTER/VNIR

Fig. 8. Images of ASTER/VNIR and Google map and layout image as well as pixels corresponding to the paddy fields $\mathrm{A}$ and $\mathrm{B}$

Therefore, the relation between NDVI and rice crop quality which is represented with protein content in rice crops is confirmed with ASTER/VNIR remote sensing satellite data. 


\section{Most Appropriate Number of Ear and Number of Rice $/ m^{2}$}

Relation between NDVI and one of the other concerns of the number of rice $/ \mathrm{m}^{2}$ is investigated. Figure 9 shows the relation. Although $R^{2}$ is not high enough, it is confirmed that the number of rice $/ \mathrm{m}^{2}$ is proportional to NDVI. Therefore, it is found that around 322 and 348 of the number of rice $/ \mathrm{m}^{2}$ would be appropriate for stump density 50 and $70 / 3.3 \mathrm{~m}^{2}$, respectively. Also, as shown in Figure 7, it is found that 414 and 464 of the number of ear(x100) $/ \mathrm{m}^{2}$ are appropriate for stump density of 50 and $70 / 3.3 \mathrm{~m}^{2}$, respectively. These are estimated with the measured NDVI.

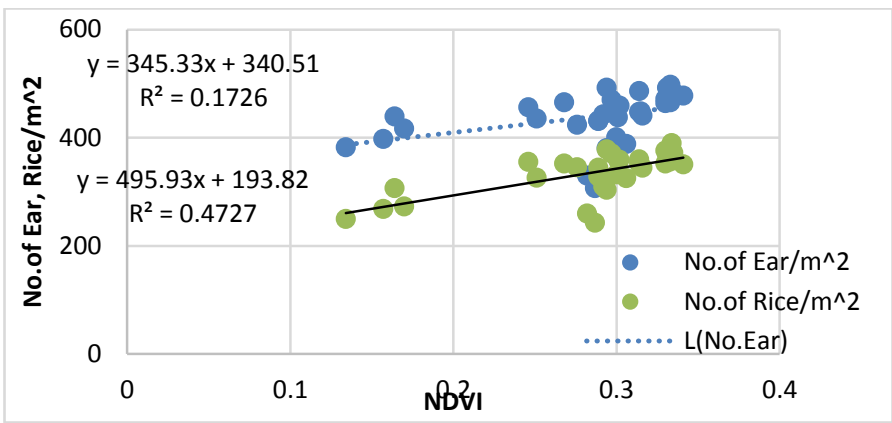

Fig. 9. Relation between NDVI and one of the other concerns of the number of ear and rice $/ \mathrm{m}^{2}$

\section{CONCLUSION}

Estimation of protein content in rice crop and nitrogen content in rice leaves through regression analysis with Normalized Difference Vegetation Index: NDVI derived from camera mounted radio-control helicopter and remote sensing satellite mounted visible to near infrared radiometers made. Through experiments at rice paddy fields which is situated at Saga Prefectural Agriculture Research Institute: SPARI in Saga city, Japan, it is found that protein content and harvest amount of rice crops is highly correlated with NDVI which is acquired with visible and Near Infrared: NIR camera mounted on radio-control helicopter and visible to near infrared radiometer onboard remote sensing satellite.

Protein content in rice crop is negatively proportional to rice taste. Therefore, rice crop quality can be evaluated through NDVI observation of rice paddy field. It is found that harvest amount is linearly proportional to NDVI. Therefore, it is possible to estimate rice crop quality and harvest amount with NDVI. It is also found that rice crop quality of low density of rice stump is better than that of highly dense rice paddy field. It is found that around 322 and 348 of the number of rice $/ \mathrm{m}^{2}$ would be appropriate for stump density 50 and 70 / $3.3 \mathrm{~m}^{2}$, respectively. Also, it is found that 414 and 464 of the number of ear(x100)/ $\mathrm{m}^{2}$ are appropriate for stump density of 50 and $70 / 3.3 \mathrm{~m}^{2}$, respectively. These can be estimated with the measured NDVI.

\section{ACKNOWLEDGEMENT}

Authors would like to thank Dr. Satoshi Tsuchida and the other related members of National Institute of Advanced Industrial Science and Technology: AIST, Japan for their providing ASTER/VNIR.

\section{REFERENCES}

[1] Wiegand, C., Shibayama, M, Yamagata, Y, Akiyama, T., 1989. Spectral Observations for Estimating the Growth and Yield of Rice, Journal of Crop Science, 58, 4, 673-683, 1989.

[2] Kohei Arai, Method for estimation of grow index of tealeaves based on Bi-Directional reflectance function:BRDF measurements with ground based netwrok cameras, International Journal of Applied Science, 2, 2, 52-62, 2011.

[3] Kohei Arai, Wireless sensor network for tea estate monitoring in complementally usage with Earth observation satellite imagery data based on Geographic Information System(GIS), International Journal of Ubiquitous Computing, 1, 2, 12-21, 2011.

[4] Kohei Arai, Method for estimation of total nitrogen and fiber contents in tealeaves with grond based network cameras, International Journal of Applied Science, 2, 2, 21-30, 2011.

[5] Kohei Arai, Method for estimation of damage grade and damaged paddy field areas sue to salt containing sea breeze with typhoon using remote sensing imagery data, International Journal of Applied Science,2,3,8492, 2011.

[6] Kohei Arai, Monte Carlo ray tracing simulation for bi-directional reflectance distribution function and grow index of tealeaves estimation, International Journal of Research and Reviews on Computer Science, 2, 6, 1313-1318, 2011.

[7] Kohei.Arai, Fractal model based tea tree and tealeaves model for estimation of well opened tealeaf ratio which is useful to determine tealeaf harvesting timing, International Journal of Research and Review on Computer Science, 3, 3, 1628-1632, 2012.

[8] Kohei.Arai, H.Miyazaki, M.Akaishi, Determination of harvesting timing of tealeaves with visible and near infrared cameradata and its application to tea tree vitality assessment, Journal of Japanese Society of Photogrammetry and Remote Sensing, 51, 1, 38-45, 2012

[9] Kohei Arai, Osamu Shigetomi, Yuko Miura, Hideaki Munemoto, Rice crop field monitoring system with radio controlled helicopter based near infrared cameras through nitrogen content estimation and its distribution monitoring, International Journal of Advanced Research in Artificial Intelligence, 2, 3, 26-37, 2013.

[10] Kohei Arai, Masanori Sakashita, Osamu Shigetomi, Yuko Miura, Estimation of Protein Content in Rice Crop and Nitrogen Content in Rice Leaves Through Regression Analysis with NDVI Derived from Camera Mounted Radio-Control Helicopter, International Journal of Advanced Research in Artificial Intelligence, 3, 3, 13-19, 2013

[11] Kohei Arai, Masanori Sakashita, Osamu Shigetomi, Yuko Miura, Estimation of Protein Content in Rice Crop and Nitrogen Content in Rice Leaves Through Regression Analysis with NDVI Derived from Camera Mounted Radio-Control Helicopter, International Journal of Advanced Research in Artificial Intelligence, 3, 3, 13-19, 2013

\section{AUTHORS PROFILE}

Kohei Arai He received BS, MS and PhD degrees in 1972, 1974 and 1982, respectively. He was with The Institute for Industrial Science and Technology of the University of Tokyo from April 1974 to December 1978 and also was with National Space Development Agency of Japan from January, 1979 to March, 1990. During from 1985 to 1987, he was with Canada Centre for Remote Sensing as a Post Doctoral Fellow of National Science and Engineering Research Council of Canada. He moved to Saga University as a Professor in Department of Information Science on April 1990. He was a councilor for the Aeronautics and Space related to the Technology Committee of the Ministry of Science and Technology during from 1998 to 2000. He was a councilor of Saga University for 2002 and 2003. He also was an executive councilor for the Remote Sensing Society of Japan for 2003 to 2005. He is an Adjunct Professor of University of Arizona, USA since 1998. $\mathrm{He}$ also is Vice Chairman of the Commission-A of ICSU/COSPAR since 2008. He is the Edito-in-Chief of IJACSA and IJISA. He wrote 33 books and published 510 journal papers as well as 450 conference papers.

http://teagis.ip.is.saga-u.ac.jp/ 